\title{
Influência dos Stakeholders na gestão e no controle das organizações esportivas
}

\author{
Influence of Stakeholders in the Management and \\ Control of Sports Organizations
}

\author{
Henrique César Melo Ribeiro ${ }^{1}$ \\ Benny Cramer Costa²
}

\begin{abstract}
Resumo
Partindo do pressuposto que os stakeholders são imprescindíveis para a gestão e controle de qualquer organização, sendo ela, privada, pública, terceiro setor, sem fins lucrativos e/ou esportiva, este estudo analisou a influência dos stakeholders na gestão e no controle das organizações esportivas. Investigaram-se oito organizações esportivas, por meio do método de estudo de caso múltiplo, mediante entrevistas. Para a análise dos dados, utilizou-se primeiramente a análise intracasos e, a posteriori, a análise intercasos. Verificou-se, de maneira geral, que os stakeholders têm influência mais na gestão do que no controle das organizações esportivas, e, em especial, os stakeholders internos, como é o caso dos gestores e colaboradores. Destacam-se também os dirigentes das federações, se a entidade for a confederação, como stakeholders também influentes no controle dessas entidades. Contribui-se, aqui, para robustecer na literatura acadêmica a ideia de que os stakeholders são essenciais e ativos para a gestão das organizações esportivas.
\end{abstract}

Palavras-chave: Teoria dos stakeholders. Gestão e controle. Organizações esportivas.

\section{Abstract}

Assuming that stakeholders are essential for the management and control of any organization, it is public, private, third sector, nonprofit, and sports purposes, this

Doutor em Administração de Empresas pela Universidade Nove de Julho. Afiliação: Univesidade Federal do Piauí. Brasil. Lattes: http://lattes.cnpq.br/4885629365119489 Email: hcmribeiro@ hotmail.com

2 Pós-doutorado em Administração pela Universidade de São Paulo. Afiliação: Universidade Nove de Julho e Universidade de São Paulo. Brasil. Lattes: http://lattes.cnpq.br/4524013741486821 Email: benny@hotmail.com 
study examined the influence of stakeholders in the management and control of sport organizations. Were investigated eight sports organizations, by the method of multiple case study, through interviews. For data analysis, first we used the intra-case analysis and the subsequent cross-case analysis. There was, in general, the stakeholders have influence over the management in the control of sport organizations, in particular the internal stakeholders, such as managers and employees. Noteworthy are also the leaders of the federations, if the entity is a confederation, as well as influential stakeholders, now in control of these organizations. It helps, here, to strengthen the academic literature, the idea that stakeholders are essential and active in the management of sport organizations.

Keywords: Theory of stakeholders. Management and control.Sports organizations.

\section{Introdução}

Entende-se que os stakeholders são grupos de indivíduos estratégicos e não acionistas que compõem as redes sociais das entidades, podendo ser atuantes e afetarem as organizações (CAMPOS, 2006; FASSIN, 2012), sobretudo na gestão e controle das mesmas (WEITZNER; PERIDIS, 2011).

Neste contexto, realça-se o estudo dos pesquisadores Bourne e Walker (2005), que mapearam e visualizaram o poder e a influência dos stakeholders dentro da organização. O conceito evidenciado neste estudo foi mostrado para mais de 200 gerentes de entidades. Com isso, os autores desenvolveram uma ferramenta para identificar e priorizar os stakeholders importantes para construir relações sólidas de compromisso, sendo essencial para o alcance do sucesso na gestão e no controle de uma organização.

E tal achado remete-se e centra-se também nas organizações esportivas (HEALEY, 2012), ainda que se caracterize como embrionária nesse setor (ZOUAIN; ALVES; PIERANTI, 2006), principalmente quando se destaca, por exemplo, o Conselho de Administração como stakeholder, definindo a direção da gestão, do controle e da estratégia das organizações esportivas (SHILBURY; FERKINS, 2011). 
Diante do panorama, ressalta-se a questão de pesquisa que norteou este estudo: Como acontece a influência dos stakeholders na gestão e no controle das organizações esportivas à luz da Teoria dos Stakeholders? O objetivo geral foi analisar a influência dos stakeholders na gestão e no controle das organizações esportivas à luz da teoria citada. Dado o panorama explicado anteriormente, este estudo pretende contribuir com a pesquisa acadêmica nas instâncias teóricas. Em primeiro lugar, busca analisar o efeito dos stakeholders na gestão e no controle das organizações esportivas, contribuindo com uma nova perspectiva aos estudos de gestão e controle, que, geralmente, têm como foco as organizações de maior porte. Para isso, traz o conceito stakeholder que se sustenta e se consolida por meio da Teoria dos Stakeholders (FASSIN, 2010; FRIEDMAN; MILES, 2002; KALER, 2003), dando, assim, embasamento teórico a esta pesquisa.

Reforça-se a justificativa e importância de se trabalhar neste tema pela necessidade de melhor compreender a gestão e o controle nas organizações esportivas no Brasil. Esse enfoque sobre esse tema contribuirá para a literatura acadêmica em três aspectos: (1) amplia o conhecimento dos stakeholders, visto que inclui uma nova dimensão para o problema - a das organizações esportivas; (2) amplia o conhecimento sobre a gestão e o controle, pois inclui as organizações esportivas; (3) esclarece como os stakeholders influenciam na gestão e no controle da organização neste público pesquisado.

\section{Fundamentação teórica}

Esta seção enfocará os assuntos: Teoria dos Stakeholders, e gestão e controle nas organizações esportivas, os quais darão sustentação teórica e ajudarão na discussão dos resultados.

\subsection{Teoria dos stakeholders e os stakeholders}

A Teoria dos Stakeholders (FREEMAN, 1984) pressupõe um conjunto de atores cujas decisões podem causar grande impacto nas 
organizações (PINTO; OLIVEIRA, 2004). Entende-se com isso que o foco desta teoria é a democratização das relações entre a sociedade e as entidades, substituindo assim o foco tradicional, ou seja, a capacidade da organização atender aos interesses dos acionistas (FARIA; SAUERBRONN, 2008). Para isso, será usado o conceito stakeholder, que se sustenta e se consolida por meio da Teoria dos Stakeholders (FASSIN, 2010; FRIEDMAN; MILES, 2002; KALER, 2003), dando assim, embasamento teórico a este estudo.

Realça-se que a Teoria dos Stakeholders só amadureceu recentemente (FASSIN, 2010; FRIEDMAN; MILES, 2002). A primeira aparição do termo stakeholder no campo da Administração deu-se em um memorando interno do Instituto de Pesquisa de Stanford, em 1963 (FREEMAN; REED, 1983). Porém, o termo foi difundido por Freeman e Reed no meio acadêmico somente em 1983 (FREEMAN; REED, 1983), sendo adotado pela maioria dos pesquisadores, contribuindo assim para a aceitação do termo na comunidade empresarial (FASSIN, 2008).

A definição clássica sobre stakeholders (LAPLUME; SONPAR; LITZ, 2008) foi inicialmente formulada e evidenciada em 1984, por Freeman (CARVALHO; MACHADO; MEIRELLES, 2011;JANSSON, 2005; SUNDARAM; INKPEN, 200;), por meio do livro "Strategic management: a stakeholder approach" (GOMES, 2004), ou seja, stakeholder é qualquer grupo ou indivíduo que afeta ou é afetado pelo alcance dos objetivos de uma empresa (FREEMAN, 1984).

Entretanto, de acordo com o engajamento dos stakeholders (FREITAS et al., 2012), existem duas classes: (I) os primários, que são indivíduos ou grupos cuja participação e suporte são essenciais para a sobrevivência da organização; e (II) os secundários, que afetam e são afetados pelas organizações, contudo, eles não estão engajados nas transações das empresas, sendo considerados menos essenciais para a sua perpetuidade (CLARKSON, 1995).

Rowley (1997) e Bourne e Walker (2005) enfatizam a influência que os stakeholders têm nas organizações. O primeiro construiu uma rede social das influências simultâneas dos múltiplos stakeholders, 
acomodando as diversas demandas entre eles. Ele desenvolveu uma Teoria da influência dos stakeholders, a qual contribuiu para melhor compreender suas múltiplas demandas, e, em médio prazo, ajudaria as organizações a prever e responder as ações advindas das interações dos stakeholders no complexo sistema de relações interorganizacionais. Entretanto, as empresas podem estabelecer estratégias para cada grupo de stakeholders, independentemente do quão importante seja esse grupo (FREEMAN; MCVEA, 2001). Porém, identificar e priorizar os stakeholders não são tarefas fáceis.

Entre várias abordagens possíveis, destaca-se a adotada por Mitchell, Agle e Wood (1997) segundo a qual o modelo Stakeholder Salience corresponde ao grau de prioridade concedido pelos gestores às solicitações de um determinado grupo, sendo que esse nível de prioridade depende da presença de três atributos: Poder - do stakeholder para influenciar a empresa; Legitimidade - no relacionamento do stakeholder com a empresa; e Urgência - da reivindicação do stakeholder para a empresa (figura 1).

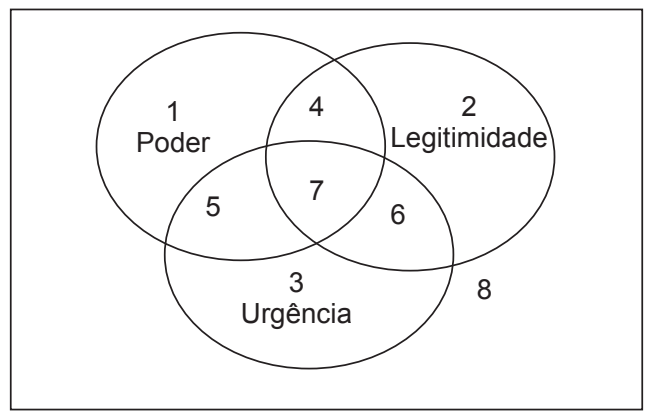

Figura 1: Nível de prioridade de stakeholders

Fonte: Mitchell, Agle e Wood (1997).

É importante realçar que a importância do stakeholder será alta quando todos estes três atributos (poder, legitimidade e urgência) são percebidos pelo gestor, sendo considerados os stakeholders que realmente são imprescindíveis para a organização, os chamados stakeholders definitivos (MELO; RÉGIS, 2012). 
Mitchell, Agle e Wood (1997) nomearam de stakeholders latentes aqueles representados nas áreas de um a três da figura, nas quais existe somente um atributo. Nas áreas quatro, cinco e seis estão os stakeholders que têm dois atributos, denominados stakeholders expectantes. Por fim, os stakeholders que estão enquadrados na área sete foram chamados de definitivos.

Abordando a Teoria dos Stakeholders e usando o modelo Stakeholder Salience como base para a investigação empírica, os autores Mainardeset al. (2010) categorizaram por importância os stakeholders em universidades. Concluíram que os governos e os acadêmicos exercem maior influência que o mercado nas universidades investigadas, e que as universidades públicas portuguesas, atualmente, se focam mais na investigação do que no ensino.

\subsection{Gestão e controle nas organizações esportivas}

A gestão (MALACRIDA; YAMAMOTO, 2006; MOYSÉS FILHO; RODRIGUES; MORETTI, 2011) e o controle (LADEIRA, 2009; RODRIGUES; MALO, 2006) são essenciais para proporcionar maior equilíbrio para as organizações (DALMÁCIO; REZENDE, 2008; MACEDO; CORRAR, 2012). Assim, influenciam a forma como as organizações são dirigidas, incluindo também as organizações esportivas (CHADWICK, 2009; FERKINS; SHILBURY, 2012; FERKINS; SHILBURY; MCDONALD, 2009; HEALEY, 2012; MICHIE; OUGHTON, 2005; TAYLOR; O'SULLIVAN, 2009; WALTERS; FERKINS; MCDONALD; SHILBURY, 2010).

Sherry, Shilbury e Wood (2007) discutiram como a relação entre esporte e negócio tem aumentado a complexidade das questões éticas que afetam a gestão do esporte contemporâneo. Em suma, os pesquisadores procuraram definir conflitos de interesses e como eles se manifestam nos negócios esportivos. Concluíram que os conflitos de interesses na gestão dos esportes podem ter os mesmos elementos estruturais que ocorrem no mundo dos negócios, contudo, a sociedade 
tem maiores expectativas no âmbito das organizações esportivas, sendo esse um dos principais pontos de diferença entre os dois cenários.

Marques e Costa (2009) fizeram um estudo comparativo entre três agremiações de futebol no estado de São Paulo: o Santos Futebol Clube, o Botafogo Futebol Clube e o Paulista Futebol Clube. Tal pesquisa foi realizada por meio de um estudo de caso múltiplo, em que foram analisadas a gestão e o controle destes clubes. Os autores verificaram que a gestão e o controle podem se constituir em importantes diferenciais competitivos para as organizações esportivas, contribuindo para a profissionalização e sua legitimação perante aos seus stakeholders.

Agora, com o enfoque no Conselho de Administração e no conflito de interesses, Sherry e Shilbury (2009) investigaram uma amostra de cinco clubes da Australian Football League por meio de entrevistas com os membros da sua comissão. Constataram ser essencial o Conselho de Administração nas organizações esportivas e o seu impacto na gestão dessas entidades, sendo importante na mitigação dos conflitos de interesse e minimizando, a posteriori, o potencial de danos para os diretores e para a organização.

Sob a ótica da gestão e controle, os autores Shilbury e Ferkins (2011) demonstraram a transição do esporte amador para um esporte profissional, em organizações esportivas da Nova Zelândia. Observaram que a gestão e o controle são essenciais para nortear as organizações esportivas, impactando na melhor compreensão das estratégias trabalhadas pelos Conselhos de Administração, e que, por sua vez, refletem-se nas tomadas de decisões futuras, tornando essas entidades mais profissionais. Fica transparente a relação e a importância da interação da gestão e do controle no esporte.

\section{Procedimentos metodológicos}

Esta pesquisa busca responder à seguinte questão de pesquisa: Como acontece a influência dos stakeholders na gestão e no controle das organizações esportivas à luz da Teoria dos Stakeholders? Ela 
contribui com a ampliação de um conhecimento generalizado sobre os temas, justificando, portanto, a pesquisa qualitativa que foi predominante neste estudo.

O método utilizado foi a pesquisa bibliográfica, com foco direcionado aos temas (constructos) correlacionados com este trabalho, utilizando autores seminais e importantes que trabalham a Teoria dos Stakeholders e a gestão e controle em organizações esportivas. Portanto, foi uma pesquisa que adotou o método de pesquisa qualitativa por meio de entrevistas com pessoas cruciais das entidades que são objeto de estudo.

Salienta-se que a utilização das entrevistas adequa-se quando é necessário explorar práticas, crenças, valores e sistemas. Além disso, quando bem utilizadas, permitem uma análise mais aperfeiçoada, coletando indícios de como os dirigentes percebem a realidade de sua respectiva organização esportiva. As entrevistas proporcionam panoramas de maior contato com o pesquisado, provocando discussões e facilitando a obtenção de respostas para a questão de pesquisa.

Portanto, a entrevista semiestruturada foi a ferramenta de coleta de dados utilizada neste estudo, proporcionando aos entrevistados a possibilidade de se colocarem na pesquisa por meio da evidenciação de suas opiniões, pois, ao provocar a reflexão sobre o juízo de valor do respondente, é possível recolher várias informações sobre os temas em debate, proporcionando respostas de maior amplitude.

\subsection{Amostra da pesquisa}

Ressalta-se que a amostra das organizações esportivas para se fazer o estudo de caso múltiplo foi feita por conveniência e oportunidade, e não para aumentar a possibilidade de inferências (CAMPOMAR, 1991). Sendo assim, foram escolhidas oito organizações esportivas, sendo quatro Confederações e quatro Federações, para se efetuar assim, oito estudos de caso. Como evidenciado antes, esta amostra foi feita por 
conveniência e oportunidade, contudo, o tamanho reduzido e intencional na escolha não permite generalizações das análises, inferências e conclusões para o restante das Confederações e Federações que não foram estudadas.

Diante do exposto, oito organizações esportivas foram escolhidas e convidadas, mediante uma carta convite assinada pelos pesquisadores, enviada por e-mail dirigido ao respectivo presidente ou ao principal executivo de cada agremiação. As oito organizações esportivas que constituíram a amostra por conveniência e oportunidade para o estudo de caso múltiplo desta pesquisa foram: Confederação Brasileira de Judô (CBJ), Confederação Brasileira de Atletismo (CBAt), Confederação Brasileira de Futsal (CBFS), Confederação Brasileira de Tênis de Mesa (CBTM), Federação Paulista de Atletismo (FPAt), Federação Paulista de Voleibol (FPV), Federação Paulista de Futsal (FPFS) e a Federação Catarinense de Tênis de Mesa (FCTM).

\subsection{Sujeitos da pesquisa}

Foram realizadas entrevistas com os dirigentes das entidades, com grande conhecimento sobre o tema pesquisado e com pontos de vista diferentes. Os dados obtidos, mediante estas entrevistas, serão de fundamental importância para compreensão do fenômeno estudado, permitindo analisar a influência dos stakeholders na gestão e no controle das organizações esportivas à luz da Teoria dos Stakeholders.

Para tanto, foram entrevistados 13 dirigentes (quadro 1), dos quais nenhum pediu anonimato, mas, de qualquer maneira, optou-se por manter todos os entrevistados no anonimato. Realça-se também que dos 13 entrevistados, seis são presidentes e os demais diretores. 
Quadro 1: Dirigentes entrevistados

\begin{tabular}{|l|l|}
\hline \multicolumn{1}{|c|}{ Nome } & \multicolumn{1}{c|}{ Função } \\
\hline Entrevistado 1 (E1) & Presidente da Confederação Brasileira de Judô \\
\hline Entrevistado 2 (E2) & Presidente da Confederação Brasileira de Futsal \\
\hline Entrevistado 3 (E3) & Presidente da Confederação Brasileira de Tênis de Mesa \\
\hline Entrevistado 4 (E4) & Presidente da Federação Paulista de Atletismo \\
\hline Entrevistado 5 (E5) & Presidente da Federação Paulista de Futsal \\
\hline Entrevistado 6 (E6) & Presidente da Federação Catarinense de Tênis de Mesa \\
\hline Entrevistado 7 (E7) & Diretor da Confederação Brasileira de Atletismo \\
\hline Entrevistado 8 (E8) & Diretor da Confederação Brasileira de Tênis de Mesa \\
\hline Entrevistado 9 (E9) & Diretor da Federação Paulista de Atletismo \\
\hline Entrevistado 10 (E10) & Diretor da Federação Paulista de Voleibol \\
\hline Entrevistado 11 (E11) & Diretor da Federação Paulista de Futsal \\
\hline Entrevistado 12 (E12) & Diretor da Federação Paulista de Futsal \\
\hline Entrevistado 13 (E13) & Diretor da Federação Paulista de Futsal \\
\hline
\end{tabular}

Fonte: Elaborado pelos autores

\subsection{Método de pesquisa e de análise dos dados}

Foi utilizado o estudo de caso como método de pesquisa para este estudo. Justifica-se o uso deste método, pois, segundo Yin (2005), um estudo de caso é uma forma de investigação empírica que estuda um fenômeno contemporâneo em seu contexto da vida real, especificamente quando os limites entre o fenômeno e o contexto não se encontram claramente determinados. Salienta-se que em situações em que os comportamentos relevantes não podem ser manipulados, mas em que é possível se fazer observações diretas e entrevistas sistemáticas, há preferência para o uso do estudo de caso (BRESSAN, 2000).

Com isso, o estudo de caso é definido como aquele que examina um fenômeno em seu ambiente natural, visando obter informações de uma ou mais entidades. Essa estratégia de pesquisa possui caráter exploratório, sendo que tal fenômeno não tem fronteiras (POZZEBON; FREITAS, 1998), podendo ser utilizada na análise intensiva de um número relativamente pequeno de situações ou de um único caso 
apenas, contudo, tanto para casos únicos como multicasos, é dada ênfase à completa descrição e ao entendimento do relacionamento dos fatores de cada estudo de caso, não importando a quantidade envolvida (CAMPOMAR, 1991).

Para a análise dos oito casos, este estudo baseou-se no trabalho de Miles e Huberman (1994). Foi realizada uma análise intracasos e intercasos, em que foi realizada, em primeiro lugar, a análise individual de cada caso (intracasos) e depois uma análise comparando os casos uns com os outros a fim de aperfeiçoar a análise dos resultados. Essa "[...] estratégia oferece base para descrições e explicações muito ricas de contextos específicos" (VIEIRA, 1997, p. 11).

\section{Análise e discussão dos resultados}

Realça-se que a apresentação e análise dos oito estudos de caso seguiram o roteiro sugerido por Miles e Huberman (1994), que aborda primeiramente a apresentação e análise de cada caso individualmente (intracasos) e, depois, a comparação dos casos, ou seja, análise intercasos.

\subsection{Análise intracasos}

Aqui se evidenciam as análises dos oito casos (MILES; HUBERMAN, 1994) sobre a influência dos stakeholders na gestão e no controle. Alguns autores, tais como Bourne e Walker (2005) e Rowley (1997), desenvolveram e confirmaram, em suas respectivas pesquisas, a influência que os stakeholders têm na organização. Especificamente na gestão (MOYSÉS FILHO; RODRIGUES; MORETTI, 2011) e no controle (LADEIRA, 2009).

\subsubsection{Confederação Brasileira de Judô}

O presidente da CBJ ressalta que:

Em todos os níveis, por exemplo, com os atletas, nós temos uma comissão de atletas. Quanto aos árbitros, 
nós temos um conselho nacional de arbitragem que pode opinar na CBJ. A influência que eles têm é sistemática, em relação aos árbitros, atletas e às federações (E1).

Em relação à influência dos stakeholders no controle da entidade, só no tocante aos presidentes das federações, ou seja, controle total, pois são para eles que prestamos contas, pois eles que têm autoridade para dizer que dará ou não dará certo alguma ação. Já quanto aos demais stakeholders, externos, não vejo como controlar. Já os stakehoders internos têm influência sim, especificamente os gestores da própria entidade, impactando na gestão e no controle da CBJ de maneira positiva, contudo, como o regime da CBJ é presidencialista, quem toma as decisões é o presidente (E1).

Observa-se que os stakeholders não têm tanta influência na gestão e no controle da entidade, excetuando-se as federações estaduais e os gestores internos da própria CBJ. Tal resultado remete a importância que estes dois tipos de stakeholders têm para esta entidade, indo ao encontro do que foi evidenciado na seção anterior, que versava sobre o relacionamento deles com a entidade, confirmando assim o papel que estes dois stakeholders têm como prioridade, ou seja, relacionado com atributo de Urgência (MITCHELL; AGLE; WOOD, 1997) para a CBJ.

\subsubsection{Confederação Brasileira de Atletismo}

O gestor da CBAt assim se posiciona:

A influência dos stakeholders na gestão da CBAt é muito grande. Nós temos nossas assembleias gerais, que são realizadas uma vez por ano, temos os fóruns, que são realizados uma vez ou duas vezes, dependendo da necessidade pra consulta, mas, tem certas coisas do dia a dia que os stakeholders não têm como influenciar. Tem decisões, financeiras que aparecem de emergência que, logicamente, se a gente puder consultar todos os stakeholders nós consultamos, mas a gente sabe que o momento de gestão, por questão de agilidade, o que nós entendemos é que o presidente e a diretoria precisam ter 
autonomia para tomar algumas decisões e justamente por isso que eles foram eleitos. Então, os dirigentes necessitam ter essa capacidade técnica para resolver os problemas de gestão $(E 7)$.

Qualquer stakeholder pode solicitar relatório, questionar qualquer decisão, e, dentro da nossa política de transparência, buscar esclarecimento. A nossa preocupação é mostrar por "a + b" por quais motivos aquela decisão foi tomada e quais resultados apresentados por aquela decisão (E7).

De maneira geral, observa-se a importância que os stakeholders têm na gestão e no controle (MITCHELL; AGLE; WOOD, 1997) desta organização esportiva. Porém, é importante ressaltar que a importância dos stakeholders é mensurada pelo nível de sua contribuição para o desempenho organizacional (CAMPOS, 2006) e que, para a CBAt, todos os envolvidos se adequam a esta afirmação.

\subsubsection{Confederação Brasileira de Futsal}

O Presidente da CBFS acredita que:

Nenhum dos stakeholders externos tem influência na gestão e/ou no controle da entidade, pois a entidade se administra pelos gestores da administração, ou seja, os gestores necessitam ter a percepção na gestão e no controle (E2).

Para o presidente da CBFS, o controle e a gestão da entidade não sofrem influência de stakeholders externos, só pelos internos, ou seja, estes últimos estão engajados no processo de gestão da entidade (FREITAS et al., 2012), sendo considerados, assim, os stakeholders primários da entidade, pois a perpetuidade da entidade é garantida pela participação e pelo suporte dos indivíduos ou grupos (CLARKSON, 1995). 


\subsubsection{Confederação Brasileira de Tênis de Mesa}

O presidente da CBTM descreve a influência dos stakeholders na gestão e no controle da CBTM assim:

Em relação à gestão, nós precisamos melhorar. $\mathrm{Na}$ CBTM é muito centralizada. Acho que precisa crescer a participação dos atletas e a participação dos treinadores, dos árbitros. Contudo, notamos que qualquer tipo de participação dos stakeholders, seja no planejamento, seja execução das ações, envolve o recurso, de telefonia, de passagem, de hospedagem e alimentação. Nós não tínhamos esse recurso no nosso plano estratégico, nunca priorizamos isso. Agora nós temos esses recursos. Nós vamos criar um Conselho de Administração pra poder agilizar as decisões estratégicas da entidade, mas isso é coisa que está latente pra 2014, é uma área que a gente sente que precisa melhorar, de ter mais gente participando do planejamento em relação às opções (E3).

No que tange ao controle, é a mesma coisa. Podemos melhorar muito. Isso é uma falha, eu diria que é um ponto fraco. Já notamos isso no nosso planejamento estratégico: a necessidade de haver mais participação dos stakeholders, tanto na gestão quanto no controle (E3).

Em relação à influência dos stakeholders na gestão e no controle da CBTM, respectivamente, a gestora afirma que:

Como temos um mapeamento que nos permite entender a função de cada um nos processos que executamos, cada stakeholder tem influência na medida do envolvimento em cada processo. Respeitamos e exigimos muito para que nossa gestão seja cada vez mais participativa, que todos opinem, para que assim, com esta abertura, possamos ter um alcance maior e com melhores resultados (E8).

Cada stakeholder, na medida de suas atribuições no processo, tem controles diferentes. Em relação aos gestores dos técnicos, árbitros e atletas, exigimos controle 
por meio de indicadores de técnicos, árbitros e dos próprios gestores. Atletas também têm que cumprir uma série de itens, que dizem respeito ao seu compromisso para com o alto nível, que é medido periodicamente e regulado por um termo de compromisso com o alto nível, entre outros pontos que demandariam tempo para expor (E8).

Analisando as percepções do presidente e da gestora CBTM, respectivamente, existe participação dos stakeholders na gestão e no controle, contudo, na medida do envolvimento de cada um no processo. No entanto, esta característica precisa melhorar na entidade, sobretudo, para as decisões estratégicas. Neste ponto, o presidente evidencia que será criado o Conselho de Administração, para focar, justamente, no âmbito estratégico da entidade, em especial no planejamento estratégico. Em suma, o Conselho de Administração (FERKINS; SHILBURY, 2012; TAYLOR; O'SULLIVAN, 2009) é importante para as organizações esportivas (FERKINS; MCDONALD; SHILBURY, 2010), especialmente na execução da estratégia (FERKINS; SHILBURY, 2012; FERKINS; SHILBURY; MCDONALD, 2009).

\subsubsection{Federação Paulista de Atletismo}

O presidente da FPA diz que:

$\mathrm{Na}$ gestão, todos os stakeholders são importantes, embora tenham uns que com menos influência e outros mais, mas todos eles são importantes. Porque se você não tem influência dos atletas, você não tem dos clubes, e, se não tem dos clubes, não tem da federação, e assim por diante (E4).

A influência da comunidade é fundamental, pois é por meio dela que surgem os atletas que vão participar de um clube, que, por sua vez, estão vinculados a uma federação e aí por diante. Todos os stakeholders são importantes para o trabalho e a sobrevivência da entidade (E4).

Poucos stakeholders têm influência no controle da entidade. Quem tem influência são: o governo, porque, 
como nós recebemos verba governamental, nós temos uma prestação de contas a ser feita, e uma interação muito grande, deles junto a nós, porque, se nós fizemos errado, nós temos que devolver dinheiro. Então, o governo são os stakeholders que fazem o controle financeiro da nossa entidade praticamente (E4).

Quanto às associações e os clubes, pelo mesmo fator, o dinheiro que eles mesmos pagam, têm que ser revertido para eles. Então quer dizer, estes três stakeholders, são fundamentais, pois têm influência no controle da entidade. Os demais stakeholders não têm influência no controle da entidade, sendo assim abortados do processo, mas é um aborto natural, não é um aborto forçado, é porque os outros stakeholders não se interessam e nem têm porque se interessar (E4).

Quanto ao outro controle, podemos dizer que a CBAt também nos controla para que nós façamos tudo dentro dos parâmetros, para que possa ter os resultados, para que ela possa ter os resultados do controle técnico, ou seja, que as competições sejam corretas, para que ela consiga ter os resultados nas competições internacionais. Em suma, a CBAt, exerce o controle junto à nossa entidade (E4).

Já o dirigente da FPA entende que:

Este nível de influência, ele vai até certo ponto, porque a confiança é em quem está executando, é na entidade, e todos os stakeholders confiam nesta entidade (E9).

Analisando a opinião do presidente da FPA, observa-se que os atletas são os stakeholders mais importantes, no que se refere ao seu envolvimento na gestão da entidade. Quanto ao controle, os stakeholders que se destacam são os governos, as associações e clubes. Deste modo, os stakeholders que influenciam são os externos, tanto para a gestão quanto para o controle. Estes indivíduos ou grupos têm algum interesse na entidade, dependendo do nível e da execução que estes stakeholders têm na entidade. Os stakeholders elencados pelo presidente são de suma importância para a continuidade da entidade, no 
contexto político e, propriamente, no esporte, que envolve os atletas, clubes e associações.

\subsubsection{Federação Paulista de Voleibol}

O dirigente da FPV constata que:

A influência destes stakeholders na gestão da minha entidade é um relacionamento, em que colocamos em discussão a avaliação da prática para os nossos associados, ou seja, clubes, entidades de práticas desportivas com que a FPV tem relação direta, e nós somos um prestador de serviço a eles. Então, toda a avaliação que vem deles para nós, em termos de como estão sendo geridas as competições, é o que nos faz avaliar se nós estamos na direção correta. Também em termos da avaliação das taxas cobradas ou da forma de elaboração de calendário é muito direto, em função dos clubes (E10).

O governo não tem gerência na nossa administração. A Federação Internacional e a CBVnos dão as diretrizes, contudo, elas não gerenciam nossa gestão. Em relação aos nossos patrocinadores, é realmente entregar o que nós nos comprometemos a fazer, ou seja, o "produto", que é a competição (E10).

O controle ocorre quando fazemos a prestação de contas, em nossa assembleia, que é anual. As associações e clubes, que tem direito a votos de aprovação na gestão financeiro-econômica da entidade, estabelecem determinado controle sobre a entidade. Mas é muito sútil (E10).

No que tange a CBV, quando existem alguns eventos no estado de São Paulo, que são coordenados pela confederação ou pela federação internacional, existe a parceria, mas, não existe influência destes stakeholders no controle sobre nossa entidade. Existe uma prestação de serviço nossa para eles (E10). 
As informações evidenciadas pelo gestor da FPV realçam a influência dos clubes e das associações na gestão e no controle da entidade, tal resultado vai ao encontro do que foi contemplado pelo presidente e pelo gestor da FPA, que enfatizam a importância destes grupos de stakeholders nas organizações esportivas. Essas informações são confirmadas pelos autores: Ferkins, Shilbury e McDonald (2009), Michie e Oughton (2005) e Walters e Chadwick (2009), os quais, em suas respectivas pesquisas, colocam em evidência os clubes e importância de suas boas práticas na profissionalização no esporte.

\subsubsection{Federação Paulista de Futsal}

Neste panorama, o presidente da FPFS, realça a influência que os stakeholders da entidade têm na gestão e no controle da organização.

Em suma, podemos dizer que a influência destes stakeholders na gestão na FPFS é tamanha que sem eles jamais poderíamos ter as condições que são necessárias para que a Federação cumprisse sua missão de desenvolvimento, de realizações, e jamais ela chegaria à condição que chegou hoje (E5).

Da mesma forma, há influência dos stakeholders no controle da entidade, já que existindo em nosso meio, a cada ano que passa sempre presentes, acreditamos que proporcionam um resultado satisfatório para todos, ao contrário do que se tem, nunca poderiam ter um retorno sempre de interesse, que exige tanto de um lado como de outro (E5).

Neste contexto, pode-se entender que as informações divulgadas pelo presidente da FPFS quanto à importância dos seus stakeholders na gestão e no controle da sua entidade vai ao encontro do que realça Mitchell, Agle e Wood (1997), quanto ao Stakeholder Salience, que corresponde ao grau de prioridade concedido pelos gestores às solicitações dos stakeholders, pelo menos em dois atributos.

Em outras palavras, os stakeholders da FPFS têm dois dos três atributos contemplados por Mitchell, Agle e Wood (1997), isto é, o poder 
que realça a influência dos stakeholders na entidade; e a legitimidade, que ressalta o relacionamento dos stakeholders com a entidade.

\subsubsection{Federação Catarinense de Tênis de Mesa}

O presidente da FCTM observa que:

Quanto à influência, no que se refere à gestão e ao controle, destacam-se os atletas, clubes e os funcionários, já os outros têm pouca ou nenhuma influência (E6).

Novamente as afirmações evidenciadas pelo presidente da FCTM confirmam o que foi visto e ressaltado pelos dirigentes das FPA e FPV no que se refere à importância e à influência dos clubes na gestão e no controle das organizações esportivas.

\subsection{Análise intercasos}

Nesta seção, contemplam-se as análises dos casos, agora os comparando (MILES; HUBERMAN, 1994), mediante uma síntese das opiniões de seus presidentes e/ou dirigentes entrevistados das suas respectivas organizações esportivas. Para facilitar essa análise comparativa, foi criada o quadro 2 , que evidencia a opinião sintética dos dirigentes sobre a questão: Como acontece a influência dos stakeholders na gestão e no controle das organizações esportivas? 
Quadro 2: Influência dos stakeholders na gestão e no controle da organização esportiva

\begin{tabular}{|c|c|}
\hline $\begin{array}{c}\text { Organizações } \\
\text { esportivas/Categorias } \\
\text { de análise }\end{array}$ & $\begin{array}{l}\text { Influência dos stakeholders na gestão e no } \\
\text { controle da organização esportiva }\end{array}$ \\
\hline CBAt & $\begin{array}{l}\text { A influência dos stakeholders na gestão da CBAt é } \\
\text { muito grande. A nossa preocupação é mostrar por "a } \\
+ \text { b" por quais motivos aquela decisão foi tomada e } \\
\text { quais resultados apresentados por aquela decisão. }\end{array}$ \\
\hline FPA & $\begin{array}{l}\text { Na gestão, todos os stakeholders são importantes, } \\
\text { embora tenham uns que exerçam menos influência } \\
\text { e outros mais, mas todos eles são importantes. } \\
\text { Poucos stakeholders têm influência no controle da } \\
\text { entidade. Quem tem influência é o governo. Outro } \\
\text { controle, podemos dizer, é o da CBAt. }\end{array}$ \\
\hline CBFS & $\begin{array}{l}\text { Nenhum dos stakeholders externos têm influência na } \\
\text { gestão e ou controle da entidade. }\end{array}$ \\
\hline FPFS & $\begin{array}{l}\text { Podemos dizer que a influência destes stakeholders } \\
\text { na gestão na FPFS é tamanha que sem eles jamais } \\
\text { poderíamos ter as condições que são necessárias } \\
\text { para cumprir nossa missão. }\end{array}$ \\
\hline CBTM & $\begin{array}{l}\text { Em relação à gestão, nós precisamos melhorar. } \\
\text { Na CBTM é muito centralizado. No que tange ao } \\
\text { controle, é a mesma coisa. Pode melhorar muito. }\end{array}$ \\
\hline FCTM & $\begin{array}{l}\text { Quanto à influência no que se refere à gestão e } \\
\text { ao controle, destacam-se os atletas, clubes e os } \\
\text { funcionários, os outros têm pouca ou nenhuma } \\
\text { influência. }\end{array}$ \\
\hline CBJ & $\begin{array}{l}\text { A influência que eles têm é sistemática, em relação } \\
\text { aos árbitros, atletas, às federações. Em relação à } \\
\text { influência dos stakeholders no controle da entidade, } \\
\text { só no tocante aos presidentes das federações. }\end{array}$ \\
\hline FPV & $\begin{array}{l}\text { A influência destes stakeholders na gestão da minha } \\
\text { entidade é um relacionamento, em que colocamos } \\
\text { em discussão a avaliação da prática. O controle } \\
\text { é quando fazemos a prestação de contas nessa } \\
\text { assembleia, que é anual. }\end{array}$ \\
\hline
\end{tabular}

Fonte: Elaborado pelos autores 
Investigando o quadro 2, em se tratando das Confederações, temos sobre o assunto: influência dos stakeholders sobre a gestão e o controle das organizações esportivas; evidência de que, das quatro confederações, três afirmam (seus dirigentes) que existe envolvimento sim, mesmo que de maneira controlada dos stakeholders na sua gestão e no seu controle. E em relação às Federações, têm-se opiniões similares dos dirigentes dessas entidades, sobretudo quando evidenciam a influência desses envolvidos na gestão.

\section{Considerações finais}

O objetivo deste estudo foi analisar a influência dos stakeholders na gestão e no controle das organizações esportivas à luz da Teoria dos Stakeholders. Para tanto, foi feita uma análise qualitativa por meio de um estudo de caso múltiplo em oito organizações esportivas, fazendo um total de 13 entrevistas. Para melhor organizar, disseminar e otimizar as análises, utilizaram-se dos métodos intracasos e intercasos concomitantemente, sugeridos por Miles e Huberman (1994).

Observou-se, de maneira geral, que os stakeholders têm influência mais na gestão do que no controle das organizações esportivas, em especial os stakeholders internos, como é o caso dos gestores e colaboradores. Destacam-se também os dirigentes das federações, se a entidade for Confederação, com stakeholders também influentes, mas agora no controle dessas entidades. Tal dado contribui e demonstra para a academia que, dependendo da organização esportiva, e da forma de influência, haverá uma respectiva classe de stakeholder para impactar, por meio de seu poder, legitimidade e/ou urgência (CLARKSON, 1995; MITCHELL; AGLE; WOOD, 1997).

Os resultados ajudam e contribuem para um melhor entendimento sobre a importância da influência dos stakeholders na gestão e no controle das organizações esportivas, possibilitando conhecer quais stakeholders são imprescindíveis para a gestão e controle dessas entidades, acarretando uma preocupação estratégica para fomentar 
seus resultados perante o cenário esportivo nacional e internacional e, sobretudo, perante a sociedade.

Conclui-se de maneira geral que, neste estudo, os stakeholders impactam na gestão e no controle das organizações esportivas investigadas. Contribui-se aqui para robustecer na literatura acadêmica internacional e, em especial, para a estrutura intelectual empírica de estudos nacionais, a ideia de que os stakeholders são preponderantes e ativos para uma boa gestão e controle das organizações esportivas e, consequentemente, contribuem para o aparecimento e difusão de estratégias nas organizações esportivas.

Outra contribuição para este estudo foi entender que os stakeholders são preponderantes para qualquer gestão organizacional, ou seja, para o setor privado, público, terceiro setor, inclusive para o esporte. Compreende-se que essa influência e sua respectiva importância não é fenômeno diferente de ocorrência nas organizações esportivas. Isto prova que os stakeholders, embasados pela Teoria dos Stakeholders, influenciam diretamente na gestão e no controle das organizações esportivas estudadas nesta pesquisa.

Ressalta-se que as considerações, contribuições e conclusões evidenciadas neste estudo não têm pretensão de esgotar o assunto, que é ainda embrionário na academia, mas sim, continuar este debate, de maneira sistêmica e estruturada, visando a modernização e profissionalização destas entidades no esporte.

A limitação deste estudo ocorreu por esta pesquisa ter trabalhado apenas entrevistas em organizações esportivas nacionais, em especial confederações e federações. Sugere-se, para futuros estudos, um alargamento e aperfeiçoamento destas entrevistas, focando não apenas as confederações e federações do esporte nacional, mas também, as entidades internacionais, em especial, as federações internacionais dos setores do esporte estudados nesta pesquisa, contribuindo com isso para a difusão, disseminação, socialização e maturação dos temas stakeholders, gestão e controle das organizações esportivas na estrutura 
intelectual da literatura acadêmica internacional e, principalmente, no panorama dos estudos nacionais.

\section{Referências}

BOURNE, L.; WALKER, D. H. T. Visualising and mapping stakeholder influence. Management Decision, USA, v. 43, n. 5/6, p. 649-660, 2005.

BRESSAN, F. O método do estudo de caso. Administração On Line, São Paulo, v. 1, n. 1, jan./fev./mar. 2000.

CAMPOMAR, M. C. Do uso de "estudo de caso" em pesquisas para dissertações e teses em Administração. Revista de Administração da USP, São Paulo, v. 26, n. 3, p. 95-97, jul./set. 1991.

CAMPOS, T. L. C. Estrutura da propriedade e desempenho econômico: uma avaliação empírica para as empresas de capital aberto no Brasil. Revista de Administração da USP, São Paulo, v. 41, n. 4, p. 369-380, out./nov./dez. 2006.

CARVALHO, J. L. R. de.; MACHADO, M. N. da M.; MEIRELLES, A. de M. Mudanças climáticas e aquecimento global: implicações na gestão estratégica de empresas do setor siderúrgico de Minas Gerais. Cadernos EBAPE.BR, São Paulo, v. 9, n. 2, p. 220-244, jun. 2011.

CLARKSON, M. B. E. A stakeholder framework for analyzing and evaluating corporate social performance. Academy of Management Review, USA, v. 20, n. 1, p. 92-117, 1995.

DALMÁCIO, F. Z.; REZENDE, A. J. A relação entre o timeliness e a utilidade da informação contábil e os mecanismos de governança corporativa: evidências no mercado acionário brasileiro. Revista de Administração e Contabilidade da UNISINOS, Rio Grande do Sul, v. 5, n. 3, p. 163-174, sep./dec. 2008.

FARIA, A.; SAUERBRONN, F. F. A responsabilidade social é uma questão de estratégia? Uma abordagem crítica. Revista de 
Administração Pública, Rio de Janeiro, v. 42, n. 1, p. 07-33, jan./ fev.2008.

FASSIN, Y. A dynamic perspective in Freeman's stakeholder model. Journal of Business Ethics, Netherlands, v. 96, n. 1, p. 39-49, Aug. 2010.

FASSIN, Y. Stakeholder management, reciprocity and stakeholder responsibility. Journal of Business Ethics, Netherlands, v. 109, n. 1, p. 83-96, Aug. 2012.

FERKINS, L.; SHILBURY, D. Good boards are strategic: what does that mean for sport governance? Journal of Sport Management, USA, v. 26, n. 1, p. 67-80, Jan. 2012.

FERKINS, L.; MCDONALD, G.; SHILBURY, D. A model for improving board performance: the case of a national sport organisation. Journal of Management \& Organization, United Kingdom, v. 16, n. 4, p. 601621, Sep. 2010.

FERKINS, L.; FERKINS, L.; MCDONALD, G. Board involvement in strategy: advancing the governance of sport organizations. Journal of Sport Management, USA, v. 23, n. 3, p. 245-277, May. 2009.

FREEMAN, R, E.; MCVEA, J. A stakeholder approach to strategic management. Social Science Research Network, USA, Working Paper n. 1/2, Jan. 2001.

FREEMAN, R, E.; REED, D. L. Stockholders and takeholders: a new perspective on corporate governance. California Management Review, USA, v. 25, n. 3, p. 88-106, Spring 1983.

FREEMAN, R, E. Strategic management: a stakeholder approach. Boston: Pitman, 1984.

FREITAS, A. R.; CABRAL, A.; FONTELES, I.; PESSOA, M. N.; SANTOS, S. dos. Engajamento dos stakeholders: uma análise dos relatórios de sustentabilidade de empresas brasileiras do setor financeiro. Revista Portuguesa e Brasileira de Gestão, Lisboa, v. 11, n. 4, p. 14-25, out. 2012. 
FRIEDMAN, A. L.; MILES, S. Developing stakeholder theory. Journal of Management Studies, United Kingdom, v. 39, n. 1, p. 1-21, 2002.

GOMES, R. C. Who are the relevant stakeholders to the local government context? empirical evidences on environmental influences in the decision-making process of english local authorities. Brazilian Administration Review, Rio de Janeiro, v. 1, n. 1, p. 34-52, Jul./Dec . 2004.

HEALEY, D. Governance in sport: outside the box? Economic and Labour Relations Review, Australia, v. 23, n. 3, p. 39-60, 2012.

JANSSON, E. The stakeholder model: the influence of the ownership and governance structures. Journal of Business Ethics, Netherlands, v. 56, n. 1, p. 1-13, 2005.

KALER, J. Differentiating stakeholder theories. Journal of Business Ethics, Netherlands, v. 46, n. 1, p. 71-83, 2003.

\section{LADEIRA, D. L. Teoria dos stakeholders no contexto da} governança corporativa: um estudo de caso. 2009. 105f. Dissertação (Mestrado em Administração), Universidade FUMEC, Faculdade de Ciências Empresariais - FACE, Belo Horizonte, 2009.

LAPLUME, A. O.; SONPAR, K.; LITZ, R. A. Stakeholder theory: reviewing a theory that moves us. Journal of Management, USA, v. 34, n. 6, p. 1152-1189, 2008.

MACEDO, M. A. da S.; CORRAR, L. J. Análise comparativa do desempenho contábil-financeiro de empresas com boas práticas de governança corporativa no Brasil. Revista de Contabilidade e Controladoria, Paraná, v. 4, n. 1, p. 42-61, 2012.

MAINARDES, E. W.; ALVES, H.; RAPOSO, M.; DOMINGUES, M. J. Categorização por importância dos stakeholders das universidades. Revista Ibero-Americana de Estratégia-RIAE, São Paulo, v. 9, n. 3, p. 04-43, set./dez. 2010. 
MALACRIDA, M. J. C.; YAMAMOTO, M. M. Governança corporativa: nível de evidenciação das informações e sua relação com a volatilidade das ações do Ibovespa. Revista Contabilidade \& Finanças - USP, São Paulo, Edição Comemorativa, p. 65-79, set. 2006.

MARQUES, D. S. P.; COSTA, A. L. Governança em clubes de futebol: um estudo comparativo de três agremiações no estado de São Paulo. Revista de Administração da USP, São Paulo, v. 44, n. 2, p. 118-130, abr./maio/jun. 2009.

MELO, P. T. N. B. de; RÉGIS, H. P. Stakeholders relevantes no perfil dos gestores dos pontos de cultura no grande Recife. Organizações em Contexto, São Paulo, v. 8, n. 15, p. 109-136, jan/jun.2012.

MICHIE, J.; OUGHTON, C. The corporate governance of professional football clubs in England. Corporate Governance: An International Review, USA, v. 13, n. 4, p. 517-531, 2005.

MILES, M. B.; HUBERMAN, M. A. Qualitative data analysis: an expanded sourcebook. Sabe: Thousand Oaks, 1994.

MITCHELL, R. K.; AGLE, B. R.; WOOD, D. J. Toward a theory of stakeholders identification and salience: defining the principle of who and what really counts. Academy of Management Review, USA, v. 22, n. 4, p. 853-886, 1997.

MOYSÉS FILHO, J. E.; RODRIGUES, A. L.; MORETTI, S. L. A. Gestão social e ambiental em pequenas e médias empresas: influência e poder dos stakeholders. Revista Eletrônica de Administração, Rio Grande do Sul, Edição 68, v. 17, n. 1, p. 204-236, jan/abr. 2011.

PINTO, M. S. L.; OLIVEIRA, R. R. Estratégias competitivas no setor elétrico brasileiro: uma análise dos interesses e expectativas dos atores da Chesf. Revista de Administração Contemporânea, Curitiba, Edição Especial, p. 131-155, 2004.

POZZEBON, M.; FREITAS, H. M. R. de. Pela aplicabilidade: com um maior rigor científico - dos estudos de caso em sistemas de 
informação. Revista de Administração Contemporânea, Rio de Janeiro, v. 2, n. 2, p. 143-170, maio/ago.1998.

RODRIGUES, A. L.; MALO, M. C. Estruturas de governança e empreendedorismo coletivo: o caso dos doutores da alegria. Revista de Administração Contemporânea, Rio de Janeiro, v. 10, n. 3, p. 2950, July/Sept. 2006.

ROWLEY, T. J. Moving beyond dyadic ties: a network theory of stakeholder influences. Academy of Management Review, USA, v. 22, n. 4, p. 887-910, 1997.

SHERRY, E.; SHILBURY, D. Board directors and conflict of interest: a study of a sport league. European Sport Management Quarterly, United Kingdom, v. 9, n. 1, p. 47-62, 2009.

SHERRY, E.; SHILBURY, D.; WOOD, G. Wrestling with "conflict of interest" in sport management. Corporate Governance, USA, v. 7, n. 3, p. 267-277, 2007.

SHILBURY, D.; FERKINS, L. Professionalisation, sport governance and strategic capability. Managing Leisure, United Kingdom, v. 16, n. 2, p. 108-127, 2011.

SUNDARAM, A. K.; INKPEN, A. C. Stakeholder theory and "the corporate objective revisited": A reply. Organization Science, USA, v. 15, n. 3, p. 370-371, 2004.

TAYLOR, M.; O'SULLIVAN, N. How should national governing bodies of sport be governed in the UK? An Exploratory study of board structure. Corporate Governance: An International Review, USA, v. 17, n. 6, p. 681-693, 2009.

VIEIRA, M. M. F. Poder, objetivos e instituições como determinantes da definição de qualidade em organizações brasileiras e escocesas. Revista de Administração Contemporânea, Curitiba, v. 1, n. 1, p. 7-33, jan./apr. 1997. 
WALTERS, G.; CHADWICK, S. Corporate citizenship in football: delivering strategic benefits through stake holder engagement. Management Decision, USA, v. 47, n. 1, p. 51-66, 2009.

WEITZNER, D.; PERIDIS, T. Corporate governance as part of the strategic process: rethinking the role of the board. Journal of Business Ethics, Netherlands, v. 102, n. 1, p. 33-42, 2011.

YIN, R. K. Estudo de caso: planejamento e métodos. Porto Alegre: Bookman, 2005.

ZOUAIN, D. M.; ALVES, J. A. B.; PIERANTI, O. P. Relatório final de atividades do fórum de discussão permanente de políticas de esporte. Revista de Administração Pública, Rio de Janeiro, v. 40, n. 4, p. 731738, jul./ago.2006.

Data de Submissão: 03/04/16

Data de Aprovação: 05/08/16 